\title{
BMJ Open Health system factors and caesarean sections in Kosovo: a cross-sectional study
}

\author{
Ilir Hoxha, ${ }^{\oplus 1,2,3}$ Alban Fejza, ${ }^{2}$ Mrika Aliu, ${ }^{3}$ Peter Jüni, ${ }^{4}$ David C Goodman ${ }^{5}$
}

To cite: Hoxha I, Fejza A, Aliu M, et al. Health system factors and caesarean sections in Kosovo: a cross-sectional study. BMJ Open 2019;9:e026702. doi:10.1136/ bmjopen-2018-026702

- Prepublication history for this paper is available online. To view these files, please visit the journal online (http://dx.doi. org/10.1136/bmjopen-2018026702).

Received 15 September 2018 Revised 14 February 2019 Accepted 5 March 2019

Check for updates

(c) Author(s) (or their employer(s)) 2019. Re-use permitted under CC BY-NC. No commercial re-use. See rights and permissions. Published by BMJ.

${ }^{1}$ Department of Community and Family Medicine, Geisel School of Medicine at Dartmouth, Hanover, New Hampshire, USA ${ }^{2}$ Heimerer College, Prishtina, Kosovo

${ }^{3}$ Action for Mother and Children, Prishtina, Kosovo

${ }^{4}$ Applied Health Research Centre (AHRC), Li Ka Shing Knowledge Institute of St. Michael's Hospital, Department of Medicine, and Institute of Health Policy, Management and Evaluation, University of Toronto, Toronto, Ontario, Canada

${ }^{5}$ The Dartmouth Institute for Health Policy and Clinical Practice, Lebanon, New Hampshire, USA

Correspondence to

Dr llir Hoxha;

ilir.s.hoxha@dartmouth.edu

\section{ABSTRACT}

Objective To investigate the association of caesarean section rates with the health system characteristics in the public hospitals of Kosovo.

Design Cross-sectional survey.

Setting Five largest public hospitals in Kosovo. Participants 859 women with low-risk deliveries who delivered from April to May 2015 in five public hospitals in Kosovo.

Outcome measures The prespecified outcomes were the crude and adjusted OR of births delivered with caesarean section by health system characteristics such as delivery by the physician who provided antenatal care, health insurance status and other. Additional prespecified outcomes were caesarean section rates and crude ORs for delivery with caesarean in each public hospital.

Results Women with personal monthly income had increased odds for caesarean (OR 1.55, 95\% $\mathrm{Cl} 1.06$ to 2.27), as did women with private health insurance coverage (OR 3.44, 95\% $\mathrm{Cl} 1.20$ to 9.85). Women instructed by a midwife on preparation for delivery had decreasing odds (OR $0.32,95 \% \mathrm{Cl} 0.19$ to 0.51 ) while women having preference for a caesarean had increasing odds for delivery with caesarean (OR $3.84,95 \% \mathrm{Cl} 1.96$ to 7.51). The odds for caesarean increased also in the case of delivery by a physician who provided antenatal care (OR 2.06, 95\% $\mathrm{Cl} 1.16$ to 3.67 ) and delivery during office hours (OR $2.36,95 \% \mathrm{Cl} 1.37$ to 4.05 ), while delivery at the University Clinical Centre of Kosovo decreased the odds for caesarean (OR $0.46,95 \% \mathrm{Cl} 0.24$ to 0.90 ).

Conclusions We found that several health system characteristics are associated with the increase of caesarean sections in a low-risk population of delivering women in public hospitals of Kosovo. These findings should be explored further and addressed via policy measures that would tackle provision of unnecessary caesareans. The study findings could assist Kosovo to develop corrective policies in addressing overuse of caesareans and may provide useful information for other middle-income countries.

\section{INTRODUCTION}

The increase of caesarean section (CS) rates has become a global epidemic and concern. $^{1-7}$ According to WHO estimates, about 6.2 million unnecessary CSs are performed annually worldwide. ${ }^{8}$ Understanding the reasons behind the increase of

\section{Strengths and limitations of this study}

The study design, including the questionnaire design and sample selection process and criteria was based on previously published studies.

- Key Kosovar clinicians and administrators at healthcare institutions were consulted for the questionnaire and study design.

- The survey questionnaire was developed, tested and revised before data collection.

- The selection of low-risk cases reduced the variation in clinical determinants and the potential for confounding.

- The main limitations of this study are the cross-sectional nature of the survey, the relatively small sample size, and the fact that the data were collected only during a specific period of the year.

CS is critical in determining if this procedure is being used appropriately. ${ }^{1} 6$ In addition to potential adverse effects on women and newborns, ${ }^{259}$ overuse of CS shifts resources that could otherwise be used for the patient's benefit. ${ }^{1} 81011$ The published literature has identified a number of determinants that can influence CS rates. ${ }^{1212}$ These determinants act and interact at different levels of healthcare systems. ${ }^{12}$ Health insurance arrangements, national guidelines on delivery of care as well as cultural factors are examples of macrolevel characteristics which influence CS rates. ${ }^{1213}$ Ownership and teaching status of the hospital are among examples of mesolevel factors that can influence the odds for CS. ${ }^{12} 14$ Mother and newborn characteristics, physician characteristics and perinatal care influence CS rates at a microlevel. ${ }^{1}$

Kosovo too is experiencing a rapid rise in CS rates. From 2000 to 2015 , CS rates have increased from $7.5 \%$ to $27.3 \% .^{15}$ In 2015 , across public hospitals in Kosovo, CS rates ranged from $9.6 \%$ to $35.2 \%$ of total births. ${ }^{15}$ Among reasons affecting the decision for CS and thus increasing and varying CS rates in Kosovo, we found women's preferences for $\mathrm{CS}$, influence of financial incentives, a lack of 
adequate training and experience of physicians and physicians' fear of committing mistakes. ${ }^{12}$ Kosovo is a low and middle-income country, ${ }^{16}$ located in South East Europe. The country has an unclear health financing system ${ }^{17} 18$ with underfunded public healthcare institutions ${ }^{17-19}$ and growing but unregulated private sector. ${ }^{1720}$ Since 2011, healthcare reform efforts have focused around health financing reform and reorganisation of healthcare system ${ }^{17}$ and maternal care is a major priority due to high natality rate. ${ }^{21}$ Therefore, in this study, we investigated the association of CS rates with the health system characteristics in the public hospitals of Kosovo.

\section{METHODS}

\section{Survey details}

We used data from a cross-sectional survey that examined women's antenatal care and birth experience and targeted the total population of low-risk births that occurred in five public hospitals within a 2-month period. Total sample size was 859. Data were collected from April to end of May 2015 from the five largest public hospitals in Kosovo. These hospitals serve the majority (over 87\%) of obstetrical patients that deliver in public hospitals in Kosovo. ${ }^{22-24}$

The survey was fielded by a non-governmental organisation. A survey questionnaire was developed, tested and revised before the data collection. Data collectors (junior residents in participating hospitals) were trained and then monitored on a weekly basis by the project team throughout the data collection period. Eligible women were identified after their delivery. Interviewers first reviewed the charts of all deliveries to assess eligibility. When found eligible, women were informed of the study and asked for a written consent. The data were collected from patients' medical records and through direct interviews (in the postdelivery period). Women were interviewed on average 1 day after the delivery, earliest on the same day of delivery and latest 12 days after delivery. The interviewer had to ensure that the women were in condition and willing to take part in the interview. Both the medical record and patient interview data were filled in the survey questionnaire by hand (paper and pencil). The data were then entered into the database.

\section{Sample selection}

The sample was selected using a modified checklist used by Coulm et $a l^{25}$ to identify low-risk pregnancies. The selection criteria were as follows: women at labour, primiparae; women without previous health conditions (such as chronic hypertension, insulin-dependent type 1 diabetes, chronic organ failure, thrombophilia, lupus erythematosus and antiphospholipid syndrome, severe epilepsy requiring treatment, seropositivity for hepatitis B or C or HIV); women who delivered after the 36th week; a newborn weight up to $3999 \mathrm{~g}$; live births; cephalic presentation of fetus; women without in vitro fertilisation; women who were younger than 36 at delivery date and no complications during delivery (ie, placenta previa, dystocia).

\section{Variables}

The survey dataset contained information on the antenatal care and birth experience of women, including maternal status, newborn status, antenatal care, predelivery care, delivery management and setting (ie, University Clinical Centre of Kosovo [UCCK]). We identified, selected, coded and recoded all variables that are known to influence the risk for $\mathrm{CS},{ }^{1} 1314$ including mother and newborn information as well as health system determinants, including the ones that we thought are particular and important for Kosovo context. Mother information included ethnicity, which like race is known to influence delivery care patterns, ${ }^{26-29}$ and was coded into Albanian ethnicity (yes/no) which represents majority of population in Kosovo. ${ }^{21}$ Age was coded to mark young delivering women ${ }^{263031}$ while body mass index (before pregnancy started) variable was calculated from weight and height data in the survey and was categorised according to WHO classification into underweight $\left(<18.5 \mathrm{~kg} / \mathrm{m}^{2}\right)$, normal range $\left(18.5-24.99 \mathrm{~kg} / \mathrm{m}^{2}\right)$, overweight $(25-29.99 \mathrm{~kg}$ / $\left.\mathrm{m}^{2}\right)$ and obese $\left(\geq 30 \mathrm{~kg} / \mathrm{m}^{2}\right){ }^{32}$ The pregnancy problems reported by mothers variable recorded any issues reported by mothers during interview but did not include any of the exclusion criteria based on which we selected the sample. Variables high school or higher education ( $\geq 12$ years) and urban residence serve as reliable indicators of the social status of women. Newborn information included weight $\geq 2500 \mathrm{~g}$ which distinguished between low and normal weight newborns ${ }^{2630}$ and $>41$ weeks of gestation which recorded if the newborn was late term or postterm as defined by the latest classification. ${ }^{33}$

Several variables measured the influence of financial incentives, including three variables which described the physician-patient interaction during antenatal care and delivery. The first (any antenatal care visit in the private sector) was a dichotomy of utilisation of care in private sector (yes/no). The second variable (majority of antenatal care visits in private sector, $>50 \%$ ) was dichotomised to distinguish between women who had received more than $50 \%$ of antenatal care visits in private institutions and those who had received $50 \%$ or less. The last variable (delivery by the physician who provided antenatal care) is also a binary variable recording whether the supervision of the delivery was performed by a physician who provided antenatal care. First two variables would test the effect of private care during the prenatal period. Last variable assessed the assumption that women use antenatal services to ensure that attending physicians will take good care of them (in the form of CS) during delivery in a public hospital. We have also included personal monthly income and health insurance coverage as variables which are known to shape the behaviour of providers in the delivery of care. ${ }^{13} 34$ The personal monthly income variable was dichotomised into women who received income (ie, had a job), and women who did not receive income 
(ie, did not have a job). A major part of the female population in Kosovo does not work, and women receiving personal income would be considered to have a higher socioeconomic status. ${ }^{35}$ Health insurance coverage refers to insurance provided by private companies, which are known to increase the risk for $\mathrm{CS} .{ }^{13}$ Referred by another healthcare facility is an indicator of how a physician treats the women from other hospitals that have not visited them in private practices. Residence in catchment area of hospital could also measure similar effect but at larger scale.

We have included several other health system and health service provision characteristics which are known to influence the risk for CS. ${ }^{1}$ The variable (provision of antenatal care by a single physician) is a binary variable reporting on whether care was provided by the same physician all along during antenatal care (yes/no). The women instructed by a midwife on preparation for delivery variable recorded if women had received advice from nurses on how to prepare for delivery in terms of hygiene, mental preparation, how they should participate during labour and similar. Maternal preference is often a strong CS decision predictor ${ }^{1}$ and a dichotomised variable mother or family requesting CS measured if the mother has asked for CS and if the family was involved in such a request, which is quite typical in Kosovo context. We were also interested if women were informed about the side effects of CS that could have influenced their preference for CS, hence the variable women informed by a physician about negative effects of caesarean was included. Induction of delivery has been treated often as a procedure that may affect the risk for $\mathrm{CS},{ }^{36-38}$ while the variable treating physician had full access to patient's antenatal care records is an indicator for a common problem in Kosovo, that is, patients showing up in a delivery room without full history which creates difficulty for clinical decision-making. The delivery during office hours variable was constructed with weekday delivery (working days vs weekend) and staff daily shift (regular, 7:00 to 15:00 hours vs on duty, ie, after 15:00 hours) information. Women who delivered during working days and regular working hours were considered to have delivered during office hours, and is a good indicator of medical staff convenience in the provision of care. ${ }^{39} 40$ We also added the variable UCCK to distinguish between a large, tertiary, national referral centre which provides the most advanced care in the country $(\mathrm{n}=1)$ and the secondary care, regional hospitals, $(n=4)$ which act as general hospitals and operate within specific regions of the country. Hospital size, type as well as level of care it provides are known to influence the risk for CS. ${ }^{1}$

\section{Outcome measures}

The prespecified outcomes were the crude and adjusted OR of births delivered with CS by health system characteristics such as delivery by the physician who provided antenatal care, health insurance status and other. Additional prespecified outcomes were CS rates and crude ORs for delivery with CS in each public hospital.

\section{Statistical analysis}

We performed descriptive analysis of mode of delivery (CS vs vaginal delivery) against several categories of variables. Crude univariable logistic regression was performed to test the unadjusted associations of variables with the odds for CS. Then, all the variables representing key health system features and mother and newborn characteristics that are known to influence CS rates and had a $\mathrm{p}<0.10$ were included in the mixed-effect model. The mixedmodel function accounts for the hospital level factor (UCCK), while allowing for random variation of other patient-level characteristics within the hospital level. The mixed-model ORs estimates are cluster-specific estimates, so interpretation is conditional to the hospital of birth. We performed $\mathrm{X}^{2}$ test and linear trend in case of ordered strata (variable body mass index). Because six variables used in the adjusted analysis had missing values, ranging from 1 to 24 missing responses per variable, the adjusted models were run using the multiple imputation method, with 20 imputations. The study is reported according to the Strengthening the Reporting of Observational Studies in Epidemiology statement for observational studies. ${ }^{41}$ Analyses were performed using IBM SPSS Statistics V.22.0 software (IBM).

\section{Patient and public involvement}

The study questionnaire was tested with patients. There was no other patient involvement in preparation or review of this study.

\section{RESULTS}

Over 20\% (178 cases) of all low-risk births were delivered via CS (table 1). CS rate ranged between $15.2 \%$ and $36.9 \%$ among hospitals. Over half of the women in the sample (435 cases) delivered within the UCCK. Most women had received antenatal care in the private sector $(790,92 \%)$ (table 2). A total of 216 women (25.1\%) were delivered by a physician who had also provided antenatal care to them. Twelve per cent (102) had requested CS by themselves or through family members.

\section{Unadjusted analysis}

Unadjusted analysis (table 2) shows that the odds for CS were increased among mothers younger than 20 years old, women living in urban locations, women living in catchment area of hospital and women that reported to have received monthly income.

All characteristics measuring antenatal care showed a small increasing (ie, any antenatal care visit in private sector, majority of antenatal care visits in private sector and pregnancy problems reported by the mother) or decreasing (ie, provision of antenatal care by a single physician) effect but did not reach statistical significance. 
Table 1 Caesarean section versus vaginal delivery among hospitals

\begin{tabular}{|c|c|c|c|c|c|}
\hline & \multirow{2}{*}{$\begin{array}{l}\text { Caesarean section } \\
\text { Events }(\%)\end{array}$} & \multirow{2}{*}{$\begin{array}{l}\text { Vaginal delivery } \\
\text { Events (\%) }\end{array}$} & \multirow{2}{*}{$\begin{array}{l}\text { Caesarean section } \\
\text { rate }(\%)\end{array}$} & \multirow[b]{2}{*}{ Crude OR $(95 \% \mathrm{Cl})$} & \multirow[b]{2}{*}{$P$ value } \\
\hline & & & & & \\
\hline \multicolumn{6}{|l|}{ Hospital } \\
\hline $\begin{array}{l}\text { Regional hospital } \\
1\end{array}$ & $28(15.7)$ & $65(9.5)$ & 30.1 & 2.41 (1.44 to 4.03$)$ & 0.001 \\
\hline $\begin{array}{l}\text { Regional hospital } \\
2\end{array}$ & $16(9.0)$ & $72(10.6)$ & 18.2 & 1.24 (0.68 to 2.27 ) & 0.480 \\
\hline $\begin{array}{l}\text { Regional hospital } \\
3\end{array}$ & $24(13.5)$ & $41(6.0)$ & 36.9 & 3.27 (1.86 to 5.77 ) & $<0.001$ \\
\hline $\begin{array}{l}\text { Regional hospital } \\
4\end{array}$ & $44(24.7)$ & $134(19.7)$ & 24.7 & 1.84 (1.19 to 2.82$)$ & 0.006 \\
\hline $\begin{array}{l}\text { University Clinical } \\
\text { Centre of Kosovo }\end{array}$ & $66(37.1)$ & $369(54.2)$ & 15.2 & 1.00 (reference) & $<0.001$ \\
\hline Total & $178(100)$ & $681(100)$ & 20.7 & & \\
\hline
\end{tabular}

Several predelivery features such as information provided to women about negative effects of CS, mother or family preference for CS, delivery by a physician who provided antenatal care and delivery during office hours showed increased odds for CS. Contrary to this, women who were instructed by midwives during preparation for delivery and delivery at the UCCK showed substantial decrease in the odds for CS.

\section{Adjusted analysis}

The adjusted analysis (table 3) confirmed the results of the unadjusted analysis. In both models, women younger than 20 years had decreased odds for CS, while for women with monthly income the odds increased, as it did for possessing private health insurance coverage. Women instructed by a midwife during the delivery preparation showed decreasing odds, while women preferring CS had increasing odds for CS delivery. The odds also increased in the case of delivery by a physician who provided antenatal care and for deliveries during office hours, while they decreased for deliveries at the UCCK.

\section{DISCUSSION}

Hospital CS rates for low-risk births varied from 15.2\% to $30.1 \%$ among hospitals. The adjusted odds for CS were increased in women with personal monthly income, if they possessed private health insurance coverage, if women preferred to deliver with CS, in case of delivery by a physician who provided antenatal care and if delivery occurred during office hours. The odds decreased if women were instructed by a midwife during delivery preparation and in case of delivery at the UCCK. The results were adjusted for age, education, urban residence, residence near the catchment area of a hospital, income, health insurance status, information provided to women by a physician, instruction of women by a midwife, preference for CS, delivery by a physician who provided antenatal care, physician access to patient's antenatal care records, delivery during office hours and UCCK.

\section{Strengths and limitations}

The study design, including the questionnaire design and sample selection process and criteria, was based on previously published studies. ${ }^{25}{ }^{42-46}$ In addition, key Kosovar clinicians and administrators at healthcare institutions were consulted for the questionnaire and study design, which was piloted before a final application. The selection of low-risk cases reduced the variation in clinical determinants and the potential for confounding. The main limitations of this study are the cross-sectional nature of the survey, the relatively small sample size and the fact that the data were collected only during a specific period of the year. The survey also did not record if the CS was emergency CS or not, therefore, we were unable to use that factor in the data analysis. Only one hospital, among five where data were collected, was a teaching hospital (ie, UCCK) which limits the generalisation of findings with regard to teaching status of hospital. Finally, women response on preference for CS may have been influenced by post-CS reporting of preference. Women are known to report a higher preference for CS after undergoing a CS as compared with reports given before the birth. ${ }^{47}$

\section{Context}

Three studies have previously examined CS rates in Kosovo but none has investigated the effect of health system factors on CS rates. ${ }^{48-50}$ In other countries, for example, Brazil, concordant with our findings, Gomes $e t$ al found a 2.51 times increase in the odds of CS $(95 \%$ CI 1.46 to 4.32 ) if the delivery was done by the same physician who provided antenatal care. ${ }^{51}$ Ribeiro $e t$ al found a weaker, although statistically significant association (RR $1.07,95 \%$ CI 1.01 to 1.14$).^{52}$ de Regt $e t a l$, in the USA, found a positive association between receiving private antenatal care and the odds of CS. ${ }^{53}$ Although maternal preference is known to influence the odds for CS, ${ }^{1}$ we have not found any studies that explicitly link maternal request to the odds for CS. Our study in Kosovo adds to the scarce evidence for such associations. 
Table 2 Caesarean section versus vaginal delivery characteristics

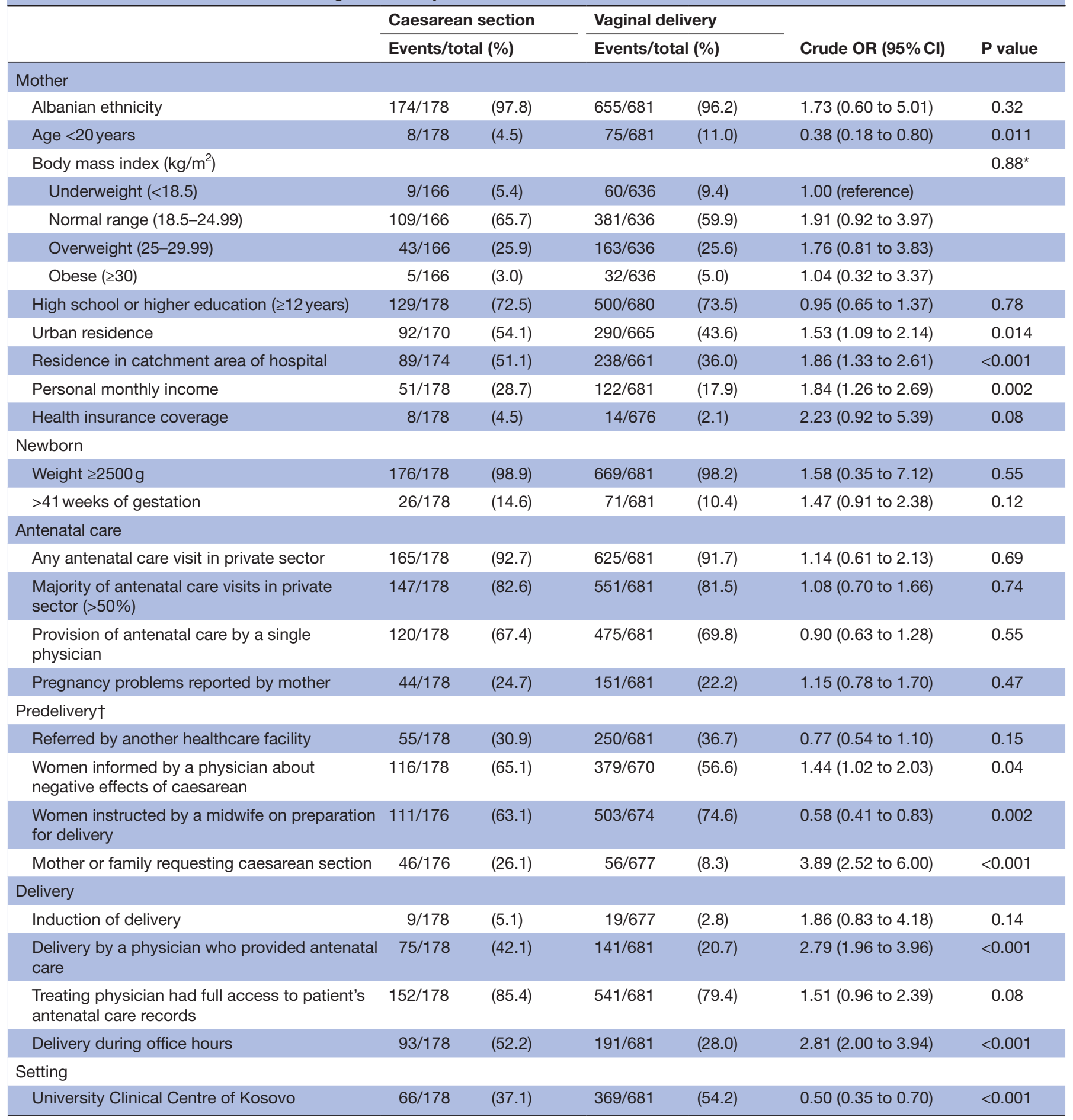

*Test for trend.

†Predelivery refers to the period after being admitted to hospital before delivery.

For other health system features, similar to our study, studies have confirmed an increasing effect on the odds for CS of women with private insurance as compared with women without insurance $2628314254-61$ or public insurance $26-29314255-5860-65$ and delivery during office hours. ${ }^{29} 394066-74$ Published studies have also confirmed a decreasing effect on CS for women taken care by a midwife during preparation for delivery ${ }^{75-80}$ as well as deliveries in a teaching hospital. ${ }^{81-85}$

\section{Mechanisms}

Although evidence shows that private care increases the odds for CS such as in the case of delivery at for-profit hospitals ${ }^{14}$ or when receiving private antenatal care ${ }^{53}$ in 
Table 3 Adjusted analysis with mixed-effects logistic regression

Adjusted OR $(95 \% \mathrm{Cl}) \quad$ P value

\begin{tabular}{|c|c|c|}
\hline \multicolumn{3}{|l|}{ Mother } \\
\hline Age $<20$ years & $0.44(0.17$ to 1.14$)$ & 0.09 \\
\hline High school or higher education ( $\geq 12$ years) & $0.75(0.50$ to 1.14$)$ & 0.18 \\
\hline Urban residence & 1.25 (0.71 to 2.20$)$ & 0.43 \\
\hline Residence in catchment area of hospital & 1.53 (0.98 to 2.39$)$ & 0.06 \\
\hline Personal monthly income & 1.55 (1.06 to 2.27$)$ & 0.03 \\
\hline Health insurance coverage & $3.44(1.20$ to 9.85$)$ & 0.02 \\
\hline \multicolumn{3}{|l|}{ Predelivery care } \\
\hline Women informed by a physician about negative effects of caesarean & 1.09 (0.56 to 2.13$)$ & 0.80 \\
\hline Women instructed by a midwife on preparation for delivery & $0.32(0.19$ to 0.51$)$ & $<0.001$ \\
\hline Mother or family requesting caesarean section & $3.84(1.96$ to 7.51$)$ & $<0.001$ \\
\hline \multicolumn{3}{|l|}{ Delivery } \\
\hline Delivery by a physician who provided antenatal care & 2.06 (1.16 to 3.67$)$ & 0.01 \\
\hline Treating physician had full access to patient's antenatal care records & 1.39 (0.80 to 2.40$)$ & 0.24 \\
\hline Delivery during office hours & 2.36 (1.37 to 4.05$)$ & $<0.001$ \\
\hline \multicolumn{3}{|l|}{ Setting } \\
\hline University Clinical Centre of Kosovo & $0.46(0.24$ to 0.90$)$ & 0.02 \\
\hline
\end{tabular}

our study, we surprisingly found a small increasing effect for private antenatal care with no significant results. Nonetheless, we found a substantial increase in the odds for delivery by physician that provided antenatal care. This finding may speak of a particular nature and interplay of financial incentives in Kosovo. While in developed countries financial incentives will play a role via institutional mechanisms and arrangements, ${ }^{13}{ }^{14}$ in low/ middle-income countries such as Kosovo, financial incentives can play via informal rewards and incentives. ${ }^{86-94} \mathrm{CS}$ in a public hospital may represent a 'reward' of 'good care' to patients who are loyal to their treating physician during antenatal care. ${ }^{12}$ The fact that CS as invasive and more resource intensive procedure would be perceived as 'good' care by women in Kosovo is a cultural phenomenon found in other contexts as well. ${ }^{95-97}$ Correspondingly, higher odds for CS in privately insured women may be influenced by the perception of patient's socioeconomic status rather than the provider's financial incentives associated with disbursement. ${ }^{1314}$

The higher odds for CS during office hours reflect physician convenience, ${ }^{39}{ }^{40}$ hospitals resource planning and cost-saving strategies ${ }^{407} 74$ or the effect of contractual arrangements with physicians. ${ }^{71}$ Higher odds in women preferring a CS could reflect cultural preferences, ${ }^{34} 98$ fear of pain during labour and birth, ${ }^{199-102}$ beliefs for the delivery at a specific time of the day ${ }^{103}$ or the desire to retain a perceived intact structure and function of the perineum. ${ }^{7499}$ Physicians are also increasingly responding more positively to such demand (ie, preference) for CS. ${ }^{104}$ The lower odds for CS in case of care by midwives reflect practice patterns among midwives that tend to avoid labour technology, ${ }^{75105106}$ or their own personal patience in delivery of care as compared with more anxious physicians. ${ }^{107}$ Availability of new technology, procedures and professional capacity, ${ }^{81-83} 108$ higher accountability due to more intense interactions during clinical decision-making, ${ }^{106}$ a systematic review of clinical decisions ${ }^{82}$ and higher compliance with clinical guidelines ${ }^{3682} 84$ are features that may explain lower rates of CS in teaching hospitals.

\section{Policy and research implications}

The fact that our study reports data from a low-risk sample that received many CSs (most likely) without a clinical need for them, does imply that in Kosovo's public hospitals we have elements of overuse ${ }^{1011}$ of CS in delivery care. This situation should be addressed in two ways. First, further research should clarify further interactions of physician with patients during antenatal care to explore in more detail incentives that may be driving overprovision of CS. Second, there is enough evidence that CSs are overused in Kosovo, and this study further confirms the need for discussion of the policy measures that could address it. In addition, as the reform process unfolds, it is also important to avoid policies which could further incentivise CS.

\section{CONCLUSION}

We found that several health system characteristics are associated with the increase of CS in a low-risk population of delivering women in the public hospitals of Kosovo. These findings should be explored further and addressed via policy measures that would tackle provision of unnecessary caesareans. The study findings could assist Kosovo 
to develop corrective policies that address overuse and improve delivery services and care. This study may also provide useful information for other middle-income countries that are likely to face similar challenges in overprovision of care.

Acknowledgements We thank Mynevere Hoxha for her input in study design; Dafina Haliti for coordinating field work; Frederik Burkle, Sejdullah Hoxha, Hossein Meyer-Troeltsch and Anila Abazi for their input and editing of the final draft of the manuscript; Arber Lama and Hossein Meyer-Troeltsch for literature review and Syzana Baja and other colleagues at Solidar Suisse for continuous support of this research project.

Contributors IH and DCG developed the idea for the study. IH, AF, PJ and DCG designed the study and the plan for analysis. $\mathrm{IH}, \mathrm{AF}$ and MA managed and supervised data collection and performed literature review. IH, AF, PJ and DCG analysed and interpreted the data. IH, AF, PJ and DCG drafted the report, which was critically reviewed by all authors.

Funding Solidar Suisse funded this study. All authors had full access to all of the data (including statistical reports and tables) in the study and take responsibility for the integrity of the data and the accuracy of the data analysis.

Competing interests None declared.

Patient consent for publication Not required.

Ethics approval This study was approved by the Ethical-Professional Committee of The Hospital and University Clinical Service of Kosovo.

Provenance and peer review Not commissioned; externally peer reviewed.

Data sharing statement № additional unpublished data are available from the study.

Open access This is an open access article distributed in accordance with the Creative Commons Attribution Non Commercial (CC BY-NC 4.0) license, which permits others to distribute, remix, adapt, build upon this work non-commercially, and license their derivative works on different terms, provided the original work is properly cited, appropriate credit is given, any changes made indicated, and the use is non-commercial. See: http://creativecommons.org/licenses/by-nc/4.0/.

\section{REFERENCES}

1. Hoxha I, Busato A, Luta X. Medical Practice Variations in Reproductive, Obstetric, and Gynecological Care. In: Johnson A, Stukel TA, Medical practice variations. Boston, MA: Springer US, 2016:141-60.

2. D'Alton ME, Hehir MP. Cesarean delivery rates: revisiting a 3-decades-old dogma. JAMA 2015;314:2238-40.

3. Betrán AP, Ye J, Moller AB, et al. The increasing trend in caesarean section rates: global, regional and national estimates: 1990-2014. PLoS One 2016;11:e0148343.

4. Boatin AA, Schlotheuber A, Betran AP, et al. Within country inequalities in caesarean section rates: observational study of 72 low and middle income countries. BMJ 2018;360:k55.

5. Molina G, Weiser TG, Lipsitz SR, et al. Relationship between cesarean delivery rate and maternal and neonatal mortality. JAMA 2015;314:2263-70.

6. Belizán JM, Minckas N, McClure EM, et al. An approach to identify a minimum and rational proportion of caesarean sections in resource-poor settings: a global network study. Lancet Glob Health 2018;6:e894-901.

7. Vogel JP, Betrán AP, Vindevoghel N, et al. Use of the Robson classification to assess caesarean section trends in 21 countries: a secondary analysis of two WHO multicountry surveys. Lancet Glob Health 2015;3:e260-70.

8. Gibbons L, Belizán JM, Lauer JA, et al. The global numbers and costs of additionally needed and unnecessary caesarean sections performed per year: overuse as a barrier to universal coverage. World health report 2010;30:1-31.

9. Keag OE, Norman JE, Stock SJ. Long-term risks and benefits associated with cesarean delivery for mother, baby, and subsequent pregnancies: Systematic review and meta-analysis. PLoS Med 2018;15:e1002494.

10. Saini V, Brownlee S, Elshaug AG, et al. Addressing overuse and underuse around the world. The Lancet 2017;390:105-7.
11. Berwick DM. Avoiding overuse - the next quality frontier. The Lancet 2017;390:102-4

12. Hoxha I. Associations of caesarean section rates with characteristics of health care systems. Bern: Medizinische Fakultät der Universität Bern, 2017.

13. Hoxha I, Syrogiannouli L, Braha M, et al. Caesarean sections and private insurance: systematic review and meta-analysis. BMJ Open 2017;7:e016600.

14. Hoxha I, Syrogiannouli L, Luta X, et al. Caesarean sections and forprofit status of hospitals: systematic review and meta-analysis. BMJ Open 2017;7:e013670.

15. Ukaj X, Paçarada M, Lulaj S, et al. Report on perinatal situation in kosovo - 2015. Kosovo: Ministry of Health, 2016.

16. Country at a Glance. Kosovo: The World Bank. 2016 http://www. worldbank.org/en/country/kosovo

17. Hoxha I, Muhaxheri E, Berisha V. A proposal for a health insurance plan: how does it affect us? Prishtina, Kosovo: Solidar Suisse, 2012.

18. Schneider P, Langenbrunner J, Cho J, et al. Kosovo health financing reform study: the World Bank. 2008

19. Stanculescu M, Neculau G, Atanasov $P$, et al. The performance of public health-care systems in South-East Europe - a comparative qualitative study. Belgrade, Serbia: Friedrich-Ebert-Stiftung, 2014

20. Marusic D, Ademi - Osmani A, Hoxha I, et al; Situation analysis at Kosovo Hospital and University Clinical Services. Prishtina, Kosovo: Lux Development, 2017.

21. Sojeva K, Uka S. Demographic changes of the Kosovo population 1948-2006. Prishtina, Kosovo: Statistical Office of Kosovo (SOK), 2008.

22. Kosovo Perinatal Report. 2000-2010. Prishtina. Kosovo: Ministry of Health, 2011.

23. Kosovo Perinatal Report. 2012. Prishtina. Kosovo: Ministry of Health, 2013.

24. Kosovo Perinatal Report. 2013. Prishtina. Kosovo: Ministry of Health, 2014

25. Coulm B, Le Ray C, Lelong N, et al. Obstetric interventions for lowrisk pregnant women in France: do maternity unit characteristics make a difference? Birth 2012;39:183-91.

26. Braveman $\mathrm{P}$, Egerter $\mathrm{S}$, Edmonston $\mathrm{F}$, et al. Racial/ethnic differences in the likelihood of cesarean delivery, California. Am J Public Health 1995;85:625-30.

27. Korst LM, Gornbein JA, Gregory KD. Rethinking the cesarean rate: how pregnancy complications may affect interhospital comparisons. Med Care 2005;43:237-45.

28. Coonrod DV, Drachman D, Hobson P, et al. Nulliparous term singleton vertex cesarean delivery rates: institutional and individual level predictors. Am J Obstet Gynecol 2008;198:694. e1-694.e11.

29. Huesch MD, Currid-Halkett E, Doctor JN. Measurement and risk adjustment of prelabor cesarean rates in a large sample of California hospitals. Am J Obstet Gynecol 2014;210:443.e1-443. e17.

30. Carayol M, Blondel B, Zeitlin J, et al. Changes in the rates of caesarean delivery before labour for breech presentation at term in France: 1972-2003. Eur J Obstet Gynecol Reprod Biol 2007;132:20-6.

31. Sebastião YV, Womack L, Vamos CA, et al. Hospital variation in cesarean delivery rates: contribution of individual and hospital factors in Florida. Am J Obstet Gynecol 2016;214:123.e1-123.e18.

32. BMI. Body mass index - BMI: World Health Organization. 2016 http://www.euro.who.int/en/health-topics/disease-prevention/ nutrition/a-healthy-lifestyle/body-mass-index-bmi

33. ACOG. ACOG Committee Opinion No 579: Definition of term pregnancy. Obstet Gynecol 2013;122:1139-40.

34. Barros FC, Vaughan JP, Victora CG. Why so many caesarean sections? The need for a further policy change in Brazil. Health Policy Plan 1986;1:19-29.

35. Mehmeti I, Dobranja D, Hashani A. Women in the workforce - an analysis of the workforce conditions for women in kosovo. Prishtina Kosovo: RIINVEST Institute, 2017.

36. Cheng Y, Carpenter A, Main E. 794: Large hospital-level variation in cesarean delivery rates during induction of labor. Am J Obstet Gynecol 2015;212:S384.

37. Ehrenthal DB, Jiang $X$, Strobino DM. Labor induction and the risk of a cesarean delivery among nulliparous women at term. Obstet Gynecol 2010;116:35-42.

38. Heffner LJ, Elkin E, Fretts RC. Impact of labor induction, gestational age, and maternal age on cesarean delivery rates. Obstet Gynecol 2003;102:287-93.

39. Clark SL, Perlin JB, Fraker S, et al. Association of obstetric intervention with temporal patterns of childbirth. Obstet Gynecol 2014;124:873-80. 
40. Grytten J, Skau I, Sørensen R. Do expert patients get better treatment than others? Agency discrimination and statistical discrimination in obstetrics. J Health Econ 2011;30:163-80.

41. von Elm E, Altman DG, Egger $M$, et al. The Strengthening the Reporting of Observational Studies in Epidemiology (STROBE) statement: guidelines for reporting observational studies. The Lancet 2007;370:1453-7.

42. Huesch MD. Association between type of health insurance and elective cesarean deliveries: New Jersey, 2004-2007. Am J Public Health 2011;101:e1-7.

43. Carayol M, Zein A, Ghosn N, et al. Determinants of caesarean section in Lebanon: geographical differences. Paediatr Perinat Epidemiol 2008;22:136-44.

44. Carayol M, Zeitlin J, Roman $\mathrm{H}$, et al. Non-clinical determinants of planned cesarean delivery in cases of term breech presentation in France. Acta Obstet Gynecol Scand 2007;86:1071-8.

45. Grant D. Physician financial incentives and cesarean delivery: new conclusions from the healthcare cost and utilization project. $J$ Health Econ 2009;28:244-50.

46. Gruber J, Owings M. Physician financial incentives and cesarean section delivery. Rand J Econ 1996;27:99-123.

47. Hellmers C, BJJor S. Psychology i. Primiparae's well-being before and after birth and relationship with preferred and actual mode of birth in Germany and the USA. 2008;26:351-72.

48. Ahmeti F, Azizi I, Hoxha S, et al. Mode of delivery and mortality among preterm newborns. Ginekol Pol 2010;81:203-7.

49. Elshani B, Daci A, Gashi S, et al. The incidence of caesarean sections in the university clinical center of kosovo. Acta Inform Med 2012;20:244-8

50. Pacarada M, Kongjeli N, Kongjeli G, et al. Birth management after in vitro fertilisation: a report of 178 cases. Niger J Med 2009;18:29-31.

51. Gomes UA, Silva AA, Bettiol $\mathrm{H}$, et al. Risk factors for the increasing caesarean section rate in Southeast Brazil: a comparison of two birth cohorts, 1978-1979 and 1994. Int J Epidemiol 1999;28:687-94.

52. Ribeiro VS, Figueiredo FP, Silva AA, et al. Why are the rates of cesarean section in Brazil higher in more developed cities than in less developed ones? Braz J Med Biol Res 2007;40:1211-20.

53. de Regt RH, Minkoff HL, Feldman J, et al. Relation of private or clinic care to the cesarean birth rate. N Engl J Med Overseas Ed 1986;315:619-24.

54. Aron DC, Gordon HS, DiGiuseppe DL, et al. Variations in riskadjusted cesarean delivery rates according to race and health insurance. Med Care 2000;38:35-44.

55. Burns LR, Geller SE, Wholey DR. The effect of physician factors on the cesarean section decision. Med Care 1995;33:365-82.

56. Grant D. Explaining source of payment differences in U.S. cesarean rates: why do privately insured mothers receive more cesareans than mothers who are not privately insured? Health Care Manag Sci 2005;8:5-17.

57. Haas JS, Udvarhelyi S, Epstein AM. The effect of health coverage for uninsured pregnant women on maternal health and the use of cesarean section. JAMA 1993;270:61

58. Kozhimannil KB, Shippee TP, Adegoke O, et al. Trends in hospitalbased childbirth care: the role of health insurance. The American journal of managed care 2013;19:e125-32.

59. Onion DK, Meyer DL, Wennberg DE, et al. Primary cesarean section rates in uninsured, Medicaid and insured populations of predominantly rural northern New England. J Rural Health 1999;15:108-12.

60. Sentell T, Chang A, Ahn HJ, et al. Maternal language and adverse birth outcomes in a statewide analysis. Women Health 2016;56:257-80.

61. Stafford RS. Cesarean section use and source of payment: an analysis of California hospital discharge abstracts. Am J Public Health 1990;80:313-5.

62. Bannister-Tyrrell M, Patterson JA, Ford JB, et al. Variation in hospital caesarean section rates for preterm births. Aust N Z J Obstet Gynaecol 2015;55:350-6.

63. Henke RM, Wier LM, Marder WD, et al. Geographic variation in cesarean delivery in the United States by payer. BMC Pregnancy Childbirth 2014;14:387.

64. Lutomski JE, Murphy M, Devane D, et al. Private health care coverage and increased risk of obstetric intervention. BMC Pregnancy Childbirth 2014:14:13.

65. Movsas TZ, Wells E, Mongoven A, et al. Does medical insurance type (private vs public) influence the physician's decision to perform Caesarean delivery? J Med Ethics 2012;38:470-3.

66. Bertollini R, DiLallo D, Spadea T, et al. Cesarean section rates in Italy by hospital payment mode: an analysis based on birth certificates. Am J Public Health 1992;82:257-61.
67. Cáceres IA, Arcaya M, Declercq E, et al. Hospital differences in cesarean deliveries in Massachusetts (US) 2004-2006: the case against case-mix artifact. PLoS One 2013;8:e57817.

68. Curtin SC, Park MM. Trends in the attendant, place, and timing of births, and in the use of obstetric interventions: United States, 1989-97. Natl Vital Stat Rep 1999;47:1-12.

69. Di Lallo D, Perucci CA, Bertollini R, et al. Cesarean section rates by type of maternity unit and level of obstetric care: an area-based study in central Italy. Prev Med 1996;25:178-85.

70. Grytten J, Monkerud L, Hagen TP, et al. The impact of hospital revenue on the increase in Caesarean sections in Norway. A panel data analysis of hospitals 1976-2005. BMC Health Serv Res 2011;11:267.

71. Mossialos E, Allin S, Karras K, et al. An investigation of Caesarean sections in three Greek hospitals: the impact of financial incentives and convenience. Eur J Public Health 2005;15:288-95.

72. Osava RH, Silva FM, Tuesta EF, et al. Cesarean sections in a birth center. Rev Saude Publica 2011;45:1036-43.

73. Librero J, Peiró S, Calderón SM. Inter-hospital variations in caesarean sections. A risk adjusted comparison in the Valencia public hospitals. J Epidemiol Community Health 2000;54:631-6.

74. Faúndes A, Cecatti JG. Which policy for caesarian sections in Brazil? An analysis of trends and consequences. Health Policy Plan 1993;8:33-42.

75. de Jonge A, Peters L, Geerts CC, et al. Mode of birth and medical interventions among women at low risk of complications: $A$ cross-national comparison of birth settings in England and the Netherlands. PLoS One 2017;12:e0180846.

76. Bolten $\mathrm{N}$, de Jonge A, Zwagerman $\mathrm{E}$, et al. Effect of planned place of birth on obstetric interventions and maternal outcomes among low-risk women: a cohort study in the Netherlands. BMC Pregnancy Childbirth 2016;16:329.

77. Brocklehurst P, Hardy P, Hollowell J, et al. Perinatal and maternal outcomes by planned place of birth for healthy women with low risk pregnancies: the Birthplace in England national prospective cohort study. BMJ 2011;343:d7400.

78. Wang Z, Sun W, Zhou H. Midwife-led care model for reducing caesarean rate: a novel concept for worldwide birth units where standard obstetric care still dominates. Journal of Medical Hypotheses and Ideas 2012;6:28-31.

79. Sakala C. Midwifery care and out-of-hospital birth settings: how do they reduce unnecessary cesarean section births? Soc Sci Med 1993;37:1233-50.

80. McLachlan HL, Forster DA, Davey MA, et al. Effects of continuity of care by a primary midwife (caseload midwifery) on caesarean section rates in women of low obstetric risk: the COSMOS randomised controlled trial. BJOG 2012;119:1483-92.

81. Rock SM. Variability and consistency of rates of primary and repeat cesarean sections among hospitals in two states. Public Health Rep 1993;108:514-6.

82. Oleske DM, Glandon GL, Giacomelli GJ, et al. The cesarean birth rate: influence of hospital teaching status. Health Serv Res 1991;26:325-37.

83. Obst TE, Nauenberg E, Buck GM. Maternal health insurance coverage as a determinant of obstetrical anesthesia care. J Health Care Poor Underserved 2001;12:177-91.

84. Liu TC, Lin HC, Chen CS, et al. Obstetrician gender and the likelihood of performing a maternal request for a cesarean delivery. Eur J Obstet Gynecol Reprod Biol 2008;136:46-52.

85. Guglielminotti J, Deneux-Tharaux C, Wong CA, et al. Hospitallevel factors associated with anesthesia-related adverse events in cesarean deliveries, New York State, 2009-2011. Anesth Analg 2016;122:1947-56

86. Barber S, Bonnet F, Bekedam H. Formalizing under-the-table payments to control out-of-pocket hospital expenditures in Cambodia. Health Policy Plan 2004;19:199-208.

87. Falkingham J, Akkazieva B, Baschieri A. Trends in out-of-pocket payments for health care in Kyrgyzstan, 2001-2007. Health Policy Plan 2010;25:427-36.

88. Cohen N. Informal payments for health care - the phenomenon and its context. Health Econ Policy Law 2012;7:285-308.

89. Williams CC, Horodnic AV. Rethinking informal payments by patients in Europe: an institutional approach. Health Policy 2017;121:1053-62.

90. Habibov N, Cheung A. Revisiting informal payments in 29 transitional countries: the scale and socio-economic correlates. Soc Sci Med 2017;178:28-37.

91. Bredenkamp C, Mendola M, Gragnolati M. Catastrophic and impoverishing effects of health expenditure: new evidence from the Western Balkans. Health Policy Plan 2011;26:349-56. 
92. Aarva P, Ilchenko I, Gorobets P, et al. Formal and informal payments in health care facilities in two Russian cities, Tyumen and Lipetsk. Health Policy Plan 2009;24:395-405.

93. Parkhurst JO, Rahman SA. Non-professional health practitioners and referrals to facilities: lessons from maternal care in Bangladesh. Health Policy Plan 2007;22:149-55.

94. Martinez-Giralt X, Barros P. Health economics: an industrial organization perspective: Routledge, 2013.

95. Savage W. The rise in cesarean section: anxiety or science? In: Chard T, Richards MPM, eds. Obstetrics in the 1990s: current controversies. London, UK: Cambridge University Press, 1992.

96. Johnson SR, Elkins TE, Strong C, et al. Obstetric decision-making: responses to patients who request cesarean delivery. Obstet Gynecol 1986;67:847-50.

97. Joseph GF, Stedman CM, Robichaux AG. Vaginal birth after cesarean section: the impact of patient resistance to a trial of labor. Am J Obstet Gynecol 1991;164:1441-7.

98. Ramires de Jesus G, Ramires de Jesus N, Peixoto-Filho FM, et al. Caesarean rates in Brazil: what is involved? BJOG: An International Journal of Obstetrics \& Gynaecology 2015;122:606-9.

99. Wiklund I, Andolf $\mathrm{E}$, Lilija $\mathrm{H}$, et al. Indications for cesarean section on maternal request--guidelines for counseling and treatment. Sex Reprod Healthc 2012;3:99-106.

100. Fuglenes D, Aas E, Botten G, et al. Why do some pregnant women prefer cesarean? The influence of parity, delivery experiences, and fear. Am J Obstet Gynecol 2011;205:45.e1-45.e9.
101. Serçekuș P, Egelioglu Cetisli N, İnci FH. Birth preferences by nulliparous women and their partners in Turkey. Sex Reprod Healthc 2015;6:182-5.

102. Mazzoni A, Althabe F, Gutierrez L, et al. Women's preferences and mode of delivery in public and private hospitals: a prospective cohort study. BMC Pregnancy Childbirth 2016;16:34.

103. Hsu KH, Liao PJ, Hwang CJ. Factors affecting Taiwanese women's choice of cesarean section. Soc Sci Med 2008;66:201-9.

104. Cotzias CS, Paterson-Brown S, Fisk NM. Obstetricians say yes to maternal request for elective caesarean section: a survey of current opinion. Eur J Obstet Gynecol Reprod Biol 2001:97:15-16.

105. Zhihua W, Wenchao S, Hong Z. Midwife-led care model for reducing caesarean rate: a novel concept for worldwide birth units where standard obstetric care still dominates. 2012;6:28-31.

106. Pel M, Heres MH, Hart AA, et al. Provider-associated factors in obstetric interventions. Eur J Obstet Gynecol Reprod Biol 1995;61:129-34.

107. Francome C, Savage W. Caesarean section in britain and the United States $12 \%$ or $24 \%$ : is either the right rate? Soc Sci Med 1993;37:1199-218.

108. Nicholson WK, Witter F, Powe NR. Effect of hospital setting and volume on clinical outcomes in women with gestational and type 2 diabetes mellitus. J Womens Health 2009;18:1567-76. 